\title{
Pengaruh Kualitas Pelayanan, Servicescape dan Harga Terhadap Kepuasan Konsumen
}

\author{
Vina Islami \\ Universitas Bina Sarana Informatika/Administrasi Bisnis \\ e-mail: vina.vii@bsi.ac.id

\begin{tabular}{ccc}
\hline Diterima & Direvisi & Disetujui \\
$07-05-2019$ & $12-07-2019$ & $03-09-2019$ \\
\hline
\end{tabular}

\begin{abstract}
Abstrak: Globalisasi sekarang memiliki dampak besar pada kehidupan masyarakat, terutama dilihat dari gaya hidup mereka. Pola pikir masyarakat yang berkembang dan berubah tidak luput dari pengaruh kemajuan teknologi. Menghadapi persaingan, perusahaan harus dapat menempatkan produknya di tengah persaingan bisnis yang ketat. Konsumen saat ini lebih pintar dan selektif dalam memilih barang dan jasa yang digunakan. Penelitian ini bertujuan untuk menguji pengaruh kualitas layanan, servicescape, dan harga terhadap kepuasan konsumen di konsumen Klinik Kecantikan Jasmine Bogor. Penelitian ini menggunakan desain penelitian survei pada responden dengan menyebarkan kuesioner kepada konsumen Klinik Kecantikan Jasmine Bogor. Populasi penelitian ini adalah masyarakat Bogor yang dirawat di Klinik Kecantikan Jasmine Bogor. Sampel dalam penelitian ini berjumlah 120 responden menggunakan teknik purposive sampling dengan kriteria responden telah melakukan perawatan di Klinik Kecantikan Jasmine Bogor dan berusia di atas 17 tahun. Teknik pengumpulan data menggunakan kuesioner dengan skala Likert, yang masing-masing telah diuji dan telah memenuhi persyaratan validitas dan reliabilitas. Analisis data menggunakan regresi linier berganda dan pengujian hipotesis menggunakan uji signifikansi parsial (uji t). Hasil analisis regresi linier berganda dengan SPSS versi 16 menunjukkan bahwa kualitas layanan, servicescape, dan harga secara parsial memiliki pengaruh positif dan signifikan terhadap kepuasan pelanggan.
\end{abstract}

Kata kunci: kualitas layanan, servicescape, harga dan kepuasan pelanggan.

\begin{abstract}
Globalization now has a big impact on people's lives, especially seen from their lifestyle. The mindset of a developing and changing society does not escape the influence of technological progress. Facing competition, companies must be able to place their products in the midst of intense business competition. Consumers today are smarter and selective in choosing the goods and services used. This study aims to examine the effect of service quality, servicescape, and prices on consumer satisfaction at consumers of Jasmine Beauty Clinic Bogor. This study used a survey research design on respondents by distributing questionnaires to consumers of Jasmine Beauty Clinic Bogor. The population of this study was the Bogor community who took care at Jasmine Beauty Clinic Bogor. The sample in this study amounted to 120 respondents using a purposive sampling technique with the criteria of respondents having done treatment at Jasmine Beauty Clinic Bogor and aged over 17 years. The data collection technique uses a questionnaire with a Likert scale, each of which has been tested and has met the validity and reliability requirements. Data analysis using multiple linear regression and hypothesis testing using the partial significance test ( $t$ test). The results of multiple linear regression analysis with SPSS version 16 show that service quality, servicescape, and prices partially have a positive and significant effect on customer satisfaction.
\end{abstract}

Keywords: service quality, servicescape, price and customer satisfaction.

\section{PENDAHULUAN}

Dalam era globalisai, konsumsi rumah tangga di Indonesia mengalami pertumbuhan yang begitu cepat. Perkembangan yang pesat menyebabkan munculnya persaingan antar perusahaan yang akan memenuhi kebutuhan para konsumen. Dewasa ini sektor jasa telah mengalami pertumbuhan yang sangat pesat, seperti halnya industri jasa di bidang kecantikan, masyarakat sendiri menyadari kecantikan merupakan kebutuhan penting yang harus dilakukan. Terlebih lagi letak geografis Indonesia yang beriklim tropis membutuhkan perawatan kulit untuk kesehatan.

Dengan adanya fenomena tersebut mendukung munculnya klinik kecantikan di Indonesia. Meningkatnya klinik kecantikan khususnya di Kota Bogor membuat persaingan semakin ketat. Langkah 
perusahaan untuk menarik minat konsumen dengan memberikan pelayanan terbaik yang diharapkan mampu menciptakan kepuasan dalam diri konsumen.

Penelitian ini menganalisis pengaruh kualitas layanan, servicescape, dan harga terhadap kepuasan konsumen pada pelanggan klinik kecantikan Jasmine Beauty Clinic Bogor. Disini peneliti tertarik untuk menggali lebih dalam permasalahan yang dihadapi oleh masyarakat khususnya konsumen klinik perawatan kecantikan. Klinik kecantikan tidak hanya menawarkan jasa perawatan yang dilakukan di dalam klinik saja akan tetapi juga menawarkan berbagai produk-produknya sebagai kelanjutan perawatan yang dilakukan di klinik. Jasmine Beauty Clinic Bogor merupakan salah satu klinik perawatan kecantikan di Bogor, yang berkonsentrasi pada bidang kesehatan kulit wajah, tubuh, dan rambut yang ditangani langsung oleh dokter dan tenaga ahli profesional dalam bidang kecantikan kulit Jasmine Beauty Clinic Bogor menjual berbagai macam produk kecantikan yang diraciknya sendiri dengan berbahan dasar alami dan aman digunakan oleh konsumennya, karena klinik ini telah terdaftar di Dinas Kesehatan Kota Bogor.

Jasmine Beauty Clinic Bogor memberikan pelayanan konsultasi oleh dokter spesialis sebelum melakukan berbagai macam treatment oleh beauty therapist dan pelayanan pembelian obat atau krim maupun kebutuhan kecantikan yang lainnya.

Selain itu, Jasmine Beauty Clinic Bogor juga memperhatikan servicescape atau lingkungan fisik. Servicescape sengaja dibuat atau diciptakan manusia sebagai dukungan atas layanan yang diberikan kepada konsumen. Servicescape sangat penting, karena pada hakikatnya dapat membungkus atau mengemas jasa yang ditawarkan oleh klinik kecantikan dan mengkomunikasikan citra eksternal tentang apa yang ada didalamnya kepada konsumen.

Penawaran harga yang terjangkau merupakan salah satu faktor yang mempengaruhi tingkat kepuasan konsumen dalam melakukan perawatan. Hal tersebut diharapkan dapat meningkatkan kepuasan bagi konsumen, serta memberikan nilai tambah agar konsumen melakukan perawatan lagi di Jasmine Beauty Clinic Bogor. Harga dan berbagai promo menarik yang diberikan Jasmine Beauty Clinic Bogor tersebut sesuai dengan manfaat dan kualitas pelayanan yang dibutuhkan konsumen seperti potongan harga, atau adanya diskon-diskon tertentu setiap harinya. Jika harga yang ditetapkan oleh sebuah klinik kecantikan tidak sesuai dengan manfaat produk atau jasa yang dirasakan, maka hal itu dapat menurunkan tingkat kepuasan konsumen pada perusahaan tersebut dan sebaliknya, jika harga yang ditetapkan oleh klinik kecantikan sesuai dengan manfaat yang diterima maka akan meningkatkan kepuasan konsumennya.

\section{Kepuasan Konsumen}

(Kotler, 2008) mendefinisikan kepuasan (satisfaction) merupakan perasaan senang atau kecewa seseorang yang timbul karena membandingkan kinerja yang dipersepsikan produk atau hasil terhadap ekspektasi mereka. Jika kinerja gagal memenuhi ekspektasi, pelanggan akan merasa tidak puas. Jika kinerja sesuai dengan ekspektasi, pelanggan akan merasa puas. Jika kinerja melebihi ekspektasi, pelanggan akan sangat puas atau senang. Sedangkan menurut Spreng et.al dalam (Tjiptono, 2007) kepuasan pelanggan dirumuskan sebagai evaluasi purnabeli, dimana persepsi terhadap kinerja alternatif produk/jasa yang dipilih memenuhi atau melebihi harapan sebelum pembelian. Apabila persepsi terhadap kinerja tidak bisa memenuhi harapan, maka yang terjadi adalah ketidakpuasan.

\section{Kualitas Pelayanan}

Menurut (Kotler, 2008) kualitas adalah totalitas fitur dan karakteristik produk atau jasa yang bergantung pada kemampuannya untuk memuaskan kebutuhan yang dinyatakan atau tersirat. Sedangkan pelayanan adalah setiap kegiatan atau manfaat yang ditawarkan oleh suatu pihak pada pihak lain dan pada dasarnya tidak berwujud, serta tidak mengakibatkan kepemilikan apapun. Sedangkan menurut Parasuraman dkk dalam (Lupiyoadi, 2013) kualitas jasa didefinisikan sebagai seberapa jauh perbedaan antara kenyataan dan harapan pelanggan atas layanan yang mereka terima.

\section{Servicescape}

(Lovelock, 2010) menyatakan kondisi fisik lingkungan layanan yang dialami oleh pelanggan memainkan peranan penting dalam membentuk pengalaman layanan dan memperkuat (atau mengurangi) kepuasan pelanggan, khususnya pada jasa dengan tingkat kontak yang tinggi dan melibatkan manusia dalam prosesnya (Lupiyoadi, 2013), mengemukakan bahwa servicescape itu sendiri diilustrasikan dengan mengkombinasikan perasaan kognitif, emosional dan juga fisiologis. Ini artinnya dari beberapa indra perasa manusia dapat digunakan sebagai alat respon dan pemberi informasi mengenai ruangan ataupun lingkungan sekitar yang dirasakan oleh manusianya. Dalam bisnis jasa, pemasar perlu menyediakan sinyal/petunjuk fisik untuk dimensi tidak berwujud dari jasa yang ditawarkan perusahaan agar dapat mendukung penentuan posisi dan citra, serta meningkatkan lingkup produk.

\section{Harga}

Menurut Kotler (2008:266) harga diartikan sebagai sejumlah uang yang dibebankan atas suatu produk atau jasa, atau jumlah dari nilai yang ditukar 
konsumen atas manfaat-manfaat karena memiliki atau menggunakan produk atau jasa tersebut. Sedangkan menurut (Dharmmesta, 2007) harga adalah jumlah uang (ditambah beberapa barang kalau mungkin) yang dibutuhkan untuk mendapatkan sejumlah kombinasi dari barang beserta layanannya.

Tabel 1. Dimensi Variabel Kualitas Pelayanan, Servicescape, Harga dan Kepuasan Konsumen

\begin{tabular}{|c|l|l|}
\hline \multirow{4}{*}{$\begin{array}{c}\text { Variabel } \\
\mathbf{X}\end{array}$} & Kualitas Pelayanan & Reablilitas, Responsivitas, Kompetensi, Akses \\
\cline { 2 - 3 } & Servicescape & $\begin{array}{l}\text { Ambient conditions, spatial layout and funtionality, } \\
\text { Sign, sybols, and artfifacts }\end{array}$ \\
\cline { 2 - 3 } & Harga & $\begin{array}{l}\text { Keterjangkauan Harga, kesesuasian harga dengan } \\
\text { kualitas produk, kesesuaina harga dengan manfaat, } \\
\text { daya saing harga }\end{array}$ \\
\hline $\begin{array}{c}\text { Variabel } \\
\mathbf{Y}\end{array}$ & $\begin{array}{l}\text { Kepuasan } \\
\text { Konsumen }\end{array}$ & Reliability, Daya Tanggap, Jaminan, Bukti Fisik \\
\hline
\end{tabular}

\section{METODOLOGI PENELITIAN}

Penelitian ini menggunakan pendekatan kuantitatif dengan metode survei. Menurut (Hartono, 2010) survei adalah metode pengumpulan data primer dengan memberikan pertanyaan-pertanyaan kepada responden individu. Kuesioner digunakan untuk mengumpulkan data dari responden yang merupakan konsumen pada Jasmine Beauty Clinic Bogor.
Populasi dalam penelitian ini adalah konsumen klinik kecantikan Estetika Jasmine

Beauty Clinic Bogor. Teknik pengambilan sampel yang digunakan dalam penelitian ini adalah purpose sampling yaitu teknik pengambilan sampel dari populasi berdasarkan kriteria tertentu (Hartono, 2010). Kriteria sampel responden pernah melakukan perawatan di Jasmine Beauty Clinic Bogor dan berusia lebih dari 17 tahun. Jumlah sampel yang diambil dalam penelitian ini adalah 120 responden.

\section{Kerangka Pemikiran}

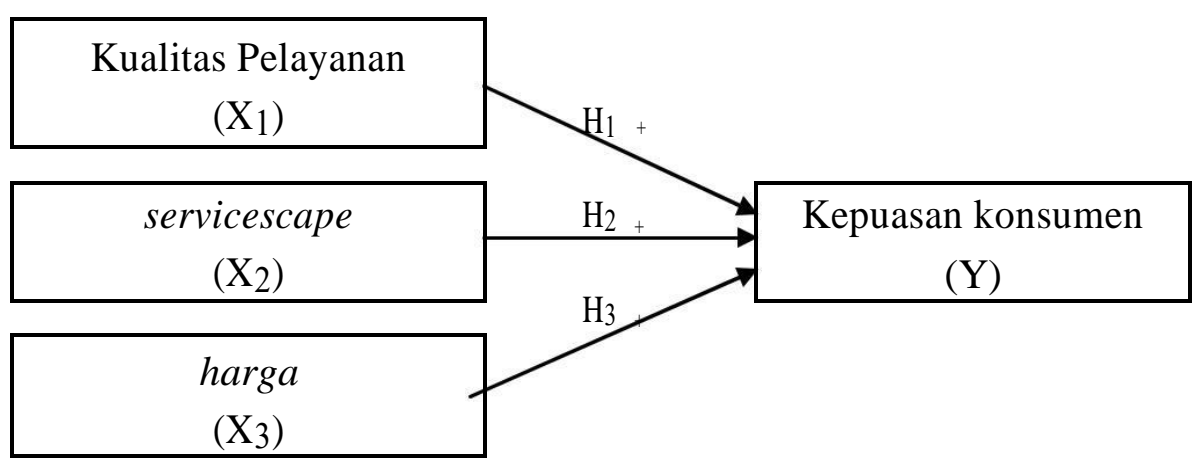

Gambar 1. Kerangka Pemikiran

Keterangan :

$\longrightarrow \quad$ : Pengaruh secara parsial (individu)

$\mathrm{H}_{1}$ : Kualitas pelayanan berpengaruh secara positif terhadap kepuasan konsumen.

$\mathrm{H}_{2}$ : Servicescape berpengaruh secara positif terhadap kepuasan konsumen.

$\mathrm{H}_{3}$ : Harga berpengaruh secara positif terhadap kepuasan konsumen. 


\section{HASIL DAN PEMBAHASAN}

\section{Hasil penelitian}

\section{a. Analisis Regresi Linier Berganda}

Pengujian hipotesis dalam penelitian ini menggunakan analisis regresi linier berganda dengan bantuan program SPSS 16.00 for Windows untuk mengetahui pengaruh variabel kualitas layanan $\left(\mathrm{X}_{1}\right)$, servicescape $\left(\mathrm{X}_{2}\right)$, harga $\left(\mathrm{X}_{3}\right)$ terhadap kepuasan konsumen (Y) secara parsial. Hasil uji regresi linier berganda dalam penelitian ini dapat dilihat pada tabel berikut:

Tabel 2

Hasil Uji Regresi Linier Berganda

\begin{tabular}{|c|c|c|c|}
\hline Variabel & $\begin{array}{c}\text { Standardized } \\
\text { Coefficients } \\
\text { Beta }\end{array}$ & Signifikansi & Keterangan \\
\hline Kualitas Pelayanan $\left(\mathbf{X}_{\mathbf{1}}\right)$ & 0,236 & 0,007 & Positif dan \\
\hline Servicescape $\left(\mathbf{X}_{\mathbf{2}}\right)$ & & & signifikan \\
\hline & 0,276 & 0,002 & Positif dan \\
\hline Harga $\left(\mathbf{X}_{\mathbf{3}}\right)$ & & & signifikan \\
\hline & 0,234 & 0,006 & Positif dan \\
\hline
\end{tabular}

Sumber : Data Primer, 2018

Berdasarkan hasil uji regresi linier berganda pada tabel 1, dapat ditulis dari hasil pengujian tersebut sebagai berikut:

$$
Y=0.236\left(X_{1}\right)+0.276\left(X_{2}\right)+0.234\left(X_{3}\right)
$$

Persamaan diatas dapat dijelaskan sebagai berikut:

1) Standardized Coefficients Beta dari variabel kualitas pelayanan sebesar 0.236 dan bertanda positif, artinya variabel kualitas pelayanan mempunyai pengaruh positif sebesar 0.236 terhadap kualitas pelayanan. Hasil ini menunjukkan bahwa semakin tinggi kualitas pelayanan yang diberikan di Jasmine Beauty Clinic Bogor maka akan meningkatkan kepuasan konsumen.

2) Standardized Coefficients Beta dari variabel servicescape sebesar 0.276 dan bertanda positif, artinya variabel servicescape mempunyai pengaruh positif sebesar 0.276 terhadap kualitas pelayanan. Hasil ini menunjukkan bahwa semakin tinggi penerapan servicescape maka akan meningkatkan kepuasan konsumen pada konsumen di Jasmine Beauty Clinic Bogor.

3) Standardized Coefficients Beta dari variabel harga sebesar 0.234 dan bertanda positif, artinya variabel harga mempunyai pengaruh positif sebesar 0.234 terhadap kualitas pelayanan. Hasil ini menunjukkan bahwa

harga yang dipersepsikan konsumen terhadap penawaran produk dan perawatan baik maka akan meningkatkan kepuasan konsumen di Jasmine Beauty Clinic Bogor.

\section{b. Uji Signifikansi}

Uji signifikansi dimaksudkan untuk mengetahui seberapa jauh pengaruh satu variabel kualitas pelayanan $\left(\mathrm{X}_{1}\right)$, servicescape $\left(\mathrm{X}_{2}\right)$, dan harga $\left(\mathrm{X}_{3}\right)$ terhadap variabel kepuasan konsumen (Y) secara parsial. Hasil uji t pada penelitian ini dapat dilihat pada tabel 1, diketahui bahwa pengaruh Kualitas Pelayanan $\left(\mathrm{X}_{1}\right)$ terhadap Kepuasan Konsumen (Y) menunjukkan nilai signifikansi sebesar 0,007. Variabel servicescape $\left(\mathrm{X}_{2}\right)$ terhadap Kepuasan Konsumen (Y) menunjukkan nilai signifikansi sebesar 0,002. Dan Variabel harga $\left(\mathrm{X}_{3}\right)$ terhadap Kepuasan Konsumen (Y) menunjukkan nilai signifikansi sebesar 0,006. Masing-masing mempunyai nilai signifikansi t lebih kecil dari taraf $5 \%(<0,05)$. Hasil ini menunjukkan bahwa variabel kualitas pelayanan $\left(\mathrm{X}_{1}\right)$, servicescape $\left(\mathrm{X}_{2}\right)$ dan harga $\left(\mathrm{X}_{3}\right)$ berpengaruh positif dan signifikan terhadap kepuasan konsumen.

\section{Pembahasan}

\section{a. Pengaruh Kualitas Pelayanan terhadap Kepuasan Konsumen}

Berdasarkan tabel 1 hasil analisis regresi linier berganda menunjukkan bahwa variabel 
kualiatas pelayanan memiliki nilai beta sebesaat 0,236 dengan nilai signifikan sebesar 0,007 . Nilai signifikansi tersebut lebih kecil dari taraf 5\% ( 0,007 $<0,05)$. Hasil penelitian pada $\mathrm{H}_{1}$ menunjukkan bahwa variabel kualitas pelayanan berpengaruh positif dan signifikan terhadap kepuasan konsumen.

Dengan demikian dapat disimpulkan konsumen memiliki sikap positif terhadap Jasmine Beauty Clinic Bogor sehingga kepuasan konsumen meningkat. Dalam penelitian ini konsumen mempersepsikan Jasmine Beauty Clinic Bogor memberikan pelayanan sesuai dengan yang dijanjikan, memberikan pelayanan yang cepat kepada konsumen, pengetahuan karyawan yang luas mengenai produk yang mereka tawarkan, memberikan perhatian yang tulus kepada konsumen, dan sarana yang diberikan klinik baik, yang berdampak pada kenyamanan konsumen, sehingga hal ini berpengaruh baik terhadap kepuasan konsumen.

\section{b. Pengaruh servicescape terhadap Kepuasan Konsumen}

Berdasarkan tabel 1 hasil analisis regresi linier berganda menunjukkan bahwa variabel servicescape memiliki nilai beta sebesar 0,276 dengan nilai signifikan sebesar 0,002. Nilai signifikansi tersebut lebih kecil dari taraf 5\% (0,002 $<0,05)$. Hasil penelitian pada $\mathrm{H}_{2}$ menunjukkan bahwa variabel servicescape berpengaruh positif dan signifikan terhadap kepuasan konsumen.

Dengan demikian dapat disimpulkan konsumen memiliki sikap positif terhadap Jasmine Beauty Clinic Bogor sehingga kepuasan konsumen meningkat. Dalam penelitian ini konsumen mempersepsikan Jasmine Beauty Clinic Bogor menunjukkan bahwa servicescape yang ada memberikan kepuasan bagi konsumen dalam melakukan perawatan. Servicescape dapat berperan penting sebagai pembentuk pengalaman dan perilaku konsumen. Kondisi sekitar yang ada di Jasmine Beauty Clinic Bogor dirasa nyaman oleh konsumen karena dibentuk dengan baik, sehingga menghasilkan lingkungan layanan yang menenangkan bagi konsumen. Ruang fungsi peralatan dan perabotan disusun dengan tepat sehingga memudahkan transaksi pelayanan bagi konsumen. Tanda, simbol dan artefak yang ada di lingkungan jasa dapat bertindak sebagai sinyal untuk mengkomunikasikan citra perusahaan, dan membantu pelanggan dalam menemukan apa yang mereka cari. Dan dapat digunakan untuk memberikan kemudahan pelanggan saat proses penghantaran berlangsung dan memudahkan konsumen dalam mendapatkan apa yang mereka cari. Dengan hal ini maka konsumen merasa puas dan tercipta kepuasan konsuemen.

\section{c. Pengaruh harga terhadap Kepuasan Konsumen}

Berdasarkan tabel 1 hasil analisis regresi linier berganda menunjukkan bahwa nilai koefisiensi regresi linier berganda sebesar 0,234 dengan nilai signifikan sebesar 0,006 . Nilai signifikansi tersebut lebih kecil dari taraf 5\% $(0,006<0,05)$. Hasil penelitian pada $\mathrm{H}_{3}$ menunjukkan bahwa variabel harga berpengaruh positif dan signifikan terhadap kepuasan konsumen.

Harga yang dibebankan kepada konsumen dinilai responden berdasarkan keterjangkauan berupa harga produk dan perawatan pada cukup terjangkau karena sesuai dengan kemampuan ekonomi masyarakat pada umumnya. Kesesuain harga produk dengan kualitas juga sesuai dengan apa yang dirasakan konsumen. Harga yang ditetapkan Jasmine Beauty Clinic Bogor lebih murah dibandingkan produk pesaing yang sejenis. Kesesuaian harga dengan manfaat dirasakan konsumen setelah melakukan perawatan. Hal tersebut menunjukkan bahwa harga memainkan peranan penting dalam mengkomunikasikan kualitas jasa yang diberikan. Semakin terjangkau harga yang ditetapkan pihak Jasmine Beauty Clinic Bogor maka kepuasan konsumen akan semakin meningkat.

\section{KESIMPULAN}

Berdasarkan hasil penelitian dan pembahasan dalam penelitian ini, menyatakan bahwa kepuasan yang dihasilkan Jasmine Beauty Clinic Bogor di persepsikan baik oleh responden, sehingga pihak Jasmine Beauty Clinic Bogor harus fokus untuk selalu meningkatkan dan mempertahankan kualitas pelayanan seperti yang diharapkan konsumen. Sehingga konsumen akan tetap merakan kepuasan ketika melakukan perawatan.

Variabel servicescape dipersepsikan baik oleh responden, sehinggan pihak Jasmine Beauty Clinic Bogor diharapkan selalu fokus untuk mempertahankan dan meningkatkan konsep servicescape yang telah ada hingga menyentuh sisi emosional pengunjung, yang berdampak pengunjung akan senantiasa merasakan kepuasan ketika melakukan perawatan di Jasmine Beauty Clinic Bogor. Servicescape yang ada di Jasmine Beauty Clinic Bogor sudah mampu menciptakan kesan positif pada diri konsumen sehinggga manfaat yang diharapkan mampu secara lebih besar dirasakan oleh konsumen.

Harga produk dan perawatan di klinik kecantikan Jasmine Beauty Clinic Bogor 
dipersepsikan baik oleh responden. Karena harga yang ditawarkan masih cukup terjangkau sesuai dengan kemampuan ekonomi masyarakat pada umumnya. Mengingat harga merupakan hal yang sangat sensitif, sebagai bahan pertimbangan pihak Jasmine Beauty Clinic Bogor untuk kedepannya lebih memperhatikan harga produk dan perawatan yang ditawarkan dengan apa yang diperoleh agar konsumen merasakan manfaat yang diberikan dan menunjukkan harga jual memiliki kualitas yang tinggi dibanding kompetitor, karena harga berpengaruh terhadap tingkat kepuasan.

\section{REFERENSI}

Dharmmesta, B. S. (2007). Azas-azas Marketing. Yogyakarta: Liberty Yogyakarta.

Hartono, J. (2010). Metode Penelitian Bisnis. Yogyakarta: BPFE.

Irawan, H. (2008). Membedah Strategi Kepuasan Pelanggan. Jakarta: Gramedia.

Kotler. (2008). Manajemen Pemasaran di Indonesia. Analisis, Perencanaan, Implementasi dan Pengendalian. Ahli Bahasa A.B Susanto,. Edisi Pertama. Jakarta: Salemba Empat.
Lembang, R. D. (2010). Analisis Pengaruh Kualitas Produk, Harga, Promosi dan Cuaca Terhadap Keputusan Pembelian Teh Siap Minum Dalam Kemasan Merek Teh Botol Sosro, Semarang. Retrieved from http://eprints.undip.ac.id/20263/2/ROSVITA_ DUA_LEMBANG.PDF.

Lovelock, et al. (2010). Pemasaran Jasa Manusia, Teknologi, Strategi-Perspektif Indonesia. Edisi 7. Jilid 2. Jakarta: Erlangga.

Lupiyoadi, R. (2013). Manajemen Pemasaran Berbasis Kompetensi. Jakarta: Salemba Empat.

Masloman, D. (2014). Kualitas pelayanan dan Servicescape Pengaruhnya Terhadap Kepuasan Konsumen pada Kentucky Fried Chicken Multamart Ranotana Manado. Jurnal EMBA, 2 no 4, 589-601.

Ransulangi, dkk. (2015). Pengaruh Kualitas Produk, Harga dan Servicescape Terhadap Kepuasan Konsumen Pengguna Rumah Makan Ocean 27 Manado. Jurnal EMBA, 3 No 3.

Tjiptono, F. (2007). Pemasaran Jasa Prinsip, Penerapan dan Penelitian. Yogyakarta: penerbit Andi. 